cell counts were decreased in most liver diseases, and we tried to clarify the causes of the decrease, especially in chronic liver diseases.

Firstly, in order to determine the role of hypersplenism in the blood cell abnormalities in liver disease, we studied the relation of excised spleen weight to blood cell counts and the effect of splenectomy on the counts in liver cirrhosis, and found that all blood cell counts had a negative correlation with spleen weight, and that red blood cell and platelet counts did not recover to the normal level after splenectomy, suggesting that a decrease in these two blood cell counts was caused not only by hypersplenism but also by liver dysfunction itself. This would be supported by the fact that a positive correlation between these cell counts and the serum albumin level was found irrespective of acute or chronic liver diseases and was not found in nephrotic syndrome. Moreover, in liver cirrhosis which showed a decrease in platelet counts, a significant difference was found in red blood cell counts between groups divided according to the serum albumin level, and in acute hepatitis with normal red blood cell counts, a significant difference was found in the serum albumin level between groups divided according to platelet counts; it could be inferred from these findings that platelet counts reflect liver dysfunction more sensitively than red blood cell counts.

From the results found in bone marrow study, decrease in production of red blood cells and platelets could be assumed to be one of the causes of the drop in their counts. The decrease in serum erythropoietin activity in liver cirrhosis would correspond to this assumption. On the other hand, it seemed possible that platelet itself was changed in character in liver cirrhosis because a significant difference was found in platelet volume in hypotonic osmotic pressure, and a case with shortened platelet survival time was found even after splenectomy.

\section{CONCLUSION}

Blood cell counts were decreased in most liver diseases. In addition to hypersplenism, liver dysfunction could be responsible for the decrease in red blood cell and platelet counts through decrease in production or changes in the cell character itself.

\section{REFERENCE}

1) Stuart, et al: New Engl J Med 292: 1310-1313, 1975.

\title{
(6) Erythrocyte Disorder in Autoimmune Diseases
}

\author{
Tokugoro Tsunematsu, MD \\ The Third Department of Internal Medicine, Shimane Medical University, \\ Izumo 693, Japan
}

\section{INTRODUCTION}

Autoimmune diseases are classified into two categories; one is organ specific and the other is organ-non-specific disease. Autoimmune hemolytic anemia (AIHA) is a representative disease of the former and systemic lupus erythematosus (SLE) is a one of the latter. In these diseases, there are many mechanisms involved in the development of erythrocyte disorders. Hemolysis is a manifestation frequently observed in these disorders. In order to clarify pathophysiology of the hemolysis, clinical and investigative studies were carried out.
These included analysis of immunoglobulin classes of autierythrocyte autoantibodies, osmotic fragility test of red cells using coil planet centrifuge, suppressor T-lymphocyte function test and electron beam irradiation on total lymphoid tissues of $\mathrm{NZB} / \mathrm{W} \mathrm{F}_{1}$.

\section{RESULTS}

1. Determination of immunoglobulins in eluates of direct Coombs' positive red cells from AIHA was performed by means of radioimmunoassay. ${ }^{1)}$ IgG was 72 to $1,524 \mathrm{ng} / \mathrm{ml}$ packed red cell (p.r.c.), IgA 20 to $163 \mathrm{ng} / \mathrm{ml}$ p.r.c., IgM 58 
to $376 \mathrm{ng} / \mathrm{ml}$ p.r.c. in 7 cases of idiopathic AIHA. IgG was 914 to $3,437 \mathrm{ng} / \mathrm{ml}$ p.r.c., $\operatorname{IgA} 7$ to 32 $\mathrm{ng} / \mathrm{ml}$ p.r.c., IgM 105 to $254 \mathrm{ng} / \mathrm{ml}$ p.r.c. in 2 cases of $\alpha$-methyl dopa induced hemolytic anemia. IgG in eluates from 4 healthy subjects was 27 to $63 \mathrm{ng} / \mathrm{ml}$ p.r.c. IgA 6.5 to $13 \mathrm{ng} / \mathrm{ml}$ p.r.c. and IgM 24 to $87 \mathrm{ng} / \mathrm{ml}$ p.r.c.

I had been recognized that IgG was a main constituent of antierythrocyte autoantibody (warm type) using immunoglobulin specific antisera. Radioimmunoassay method confirmed this finding. But IgA and IgM were also detected in the majority of cases. Pathophysical roles of these immunoglobulins are to be clarified.

2. It is well known that osmotic fragility of red cells is increased in various kinds of hemolytic anemias. Coil planet centrifuge is a method developed in Japan and is employed for osmotic fragility test using a very small amount of blood. With this method, osmotic fragility of red cells was determined on 54 healthy subjects. It ranged from $97.8 \pm 6.2 \mathrm{mOsm}$ at start point to $61.7 \pm$ $6.1 \mathrm{mOsm}$ at end point. It was found that the osmotic fragility increased in hereditary spherocytosis, AIHA and in some cases of SLE. ${ }^{2)}$ (Fig. 1) Repeated tests were made following clinical course of a case of AIHA. In a remission without overt hemolysis, osmotic fragility was almost normal but it was markedly increased in a relapse with severe hemolysis. It returned normal again after recovery from the hemolysis with treatment.
During this period, direct Coombs' test was strongly positive all the time and the semi-quantitative measurement of antierythrocyte autoantibodies using antiglobulin dilution test remained unchanged. This suggested that injurious effects on red cells might be resulted not only from the quantity of antierythrocyte autoantibody but also from other factors such as macrophage, lymphocyte functions and so forth.

3. It is known that only few $\mathrm{T}$ cells in the normal peripheral blood, either fresh $(3 \%)$ or precultured without Con A (1\%), are capable of binding autologous erythrocytes to form rosettes (autorosette). In contrast, the autorosette forming cell levels are markedly enhanced with $\mathrm{T}$ cells preincubated with Con A (30\%).

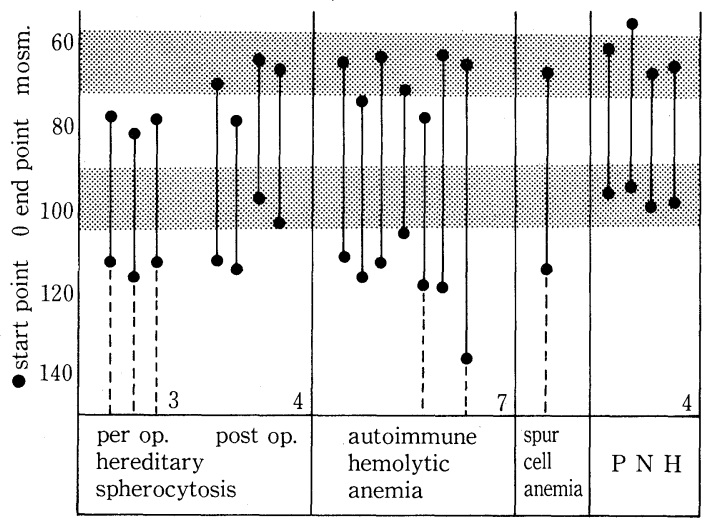

Fig. 1. Osmotic fragility of red cell in various hemolytic anemias (coil planet centrifuge).

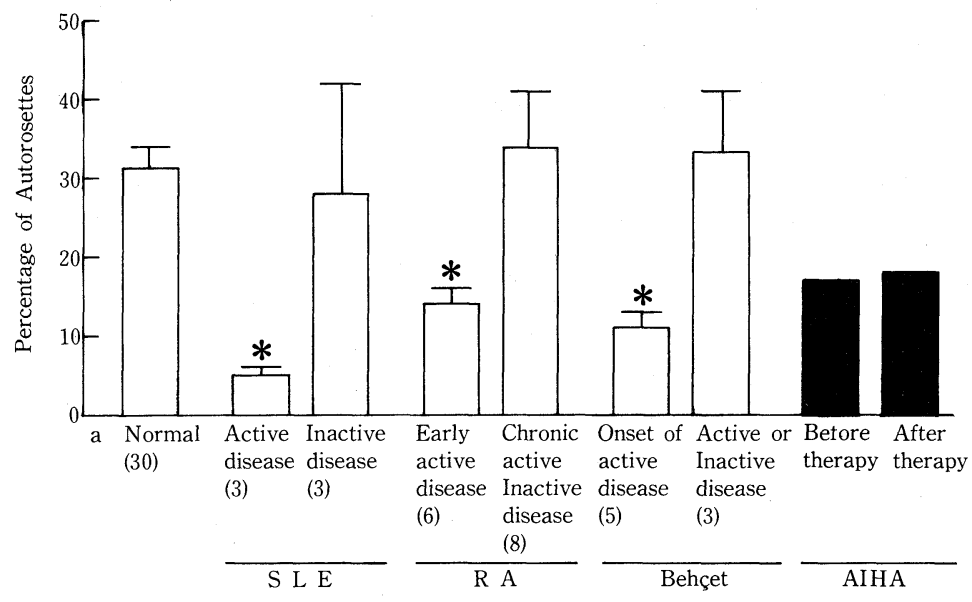

Fig. 2. Con A-Induced Autorosette Levels of T Cells.

A Study of a Patient with AIHA before and after Theropy. 
The Con A-stimulated autorosette T cells mediate suppression of the $\mathrm{T}$ cell proliferative response to mixed lymphocyte reaction (MLR) and the B cell proliferative response to pokeweed mitogen (PWM), while these cells fail to help the PWM response of the B cells. Thus, Con A-stimulated autorosette forming $\mathrm{T}$ cells belong to the suppressor cell population. From the fact that percentage of Con A-activated autorosette forming $\mathrm{T}$ cells (Con A-ARFT) correlated well with the degree of Con A-induced suppressor $\mathrm{T}$ cell function, the Con A-ARFT was used to assess the immunological states in various diseases ${ }^{3)}$. It was found that the Con-A ARFT was very low in active SLE, RA and initial stage of Behçet's disease, and it returned almost normal in inactive SLE, RA and advanced stage of Behçet's disease. In measuring the Con-A ARFT in AIHA, both autologous and homologous red cells had been used for rosette forming. The rosette forming $\mathrm{T}$ lymphocytes using both red cells were almost euqlly low. From this result, it was postulated that there was a defect of T-lymphocyte suppressor function and consequently an impairment of immunological regulation in $\mathrm{AIHA}^{4)}$. (Fig. 2)

4) $\mathrm{NZB} / \mathrm{W} F_{1}$ mice is a model animal of human SLE. Irradiation was carried out on these mice at age of 4 and 6 months. According to a regimen described by Strober et al, fractionated total lymphoid electron beam irradiation (TLI) was given ${ }^{5)}$. Linear accelerator was used to deliver 11 fractions of $200 \mathrm{rad}$ each to achieve a total dose

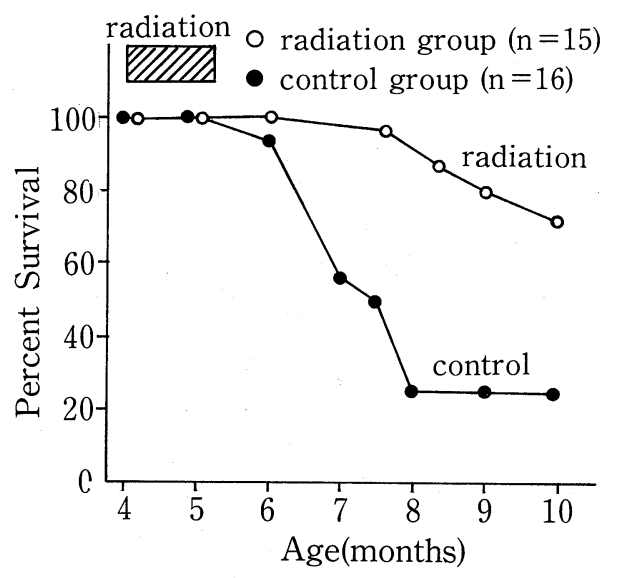

Fig. 3. Effect of treatment on the survival of NZB/NZW mice.

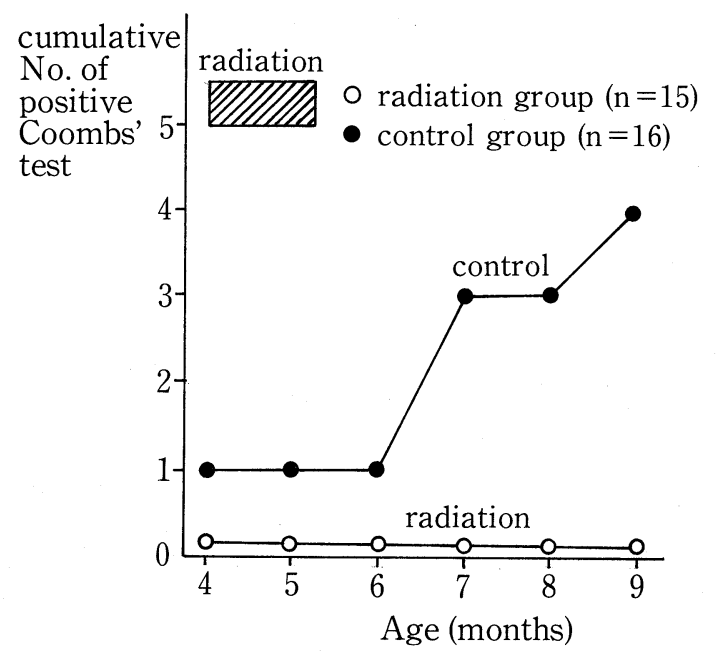

Fig. 4. Effect of treatment on development of antiery throcyte autoantibodies.

of 3,400 rad. Additional 2,000 rad to the above dose was delivered on 6 months old mice. Nonirradiated mice were served as control. The percent of 10-month survival of irradiated $F_{1}$ mice at 4 months and non-irradiated mice was $73 \%$ and $25 \%$, respectively. (Fig. 3) This prolongation of survival time in the irradiated group was associated with the inhibition of development of anemia, proteinuria and autoantibodies such as anti-DNA and anti-erythrocyte autoantibodies. (Fig. 4) It was considered that the irradiation had brought recovering effect on immunological derangement of $\mathrm{NZB} / \mathrm{W} \quad \mathrm{F}_{1}$ mice resulting in prevention of developing autoimmune diseases.

\section{CONCLUSION}

There are many mechanisms by which erythrocyte disorder develop in autoimmune diseases. In these, hemolysis is one of main mechanism. Determination of antierythrocyte autoantibodies by radioimmunoassay, osmotic fragility of red cells using CPC were presented here and pathophysiology of hemolysis in autoimmune diseases was discussed. In development of autoimmune disease, immunological derangements played important role. Regarding this, investigative results were presented with special reference to suppressor function of T-lymphocyte. And preventive effects of electron beam irradiation on develop- 
ment of autoimmune disease in $\mathrm{NZB} / \mathrm{W} \quad \mathrm{F}_{1}$ mice were reported here.

Indexing words or phrases:

Autoimmune hemolytic anemia (AIHA), systemic lupus erythematosus (SLE) direct Coombs' positive red cells, osmotic fragility of red cells antierythrocyte autoantibody (warm type), suppressor $\mathrm{T}$ cell function Con A-stimulated autorosette $\mathrm{T}$ cells, NZB/W $F_{1}$ mice fractionated total lymphoid electron beam irradiation (TLI)

\section{REFERENCES}

1) Ogawa $\mathrm{H}$, et al: Immunoglobulin classes of antierythrocyte autoantibodies in autoimmune hemolytic anemia with special reference to determination of IgG, IgA and IgM by radioimmunoassay. Annual report of the Ministry of Health and Welfare, Research Committee for Idiopathic Erythropoietic Disorders, Japan, p. 278, 1980.

2) Kannagi R, et al: A study on the erythrocyte membrane fragility in warm type autoimmune haemoly tic anemia with coil planet centrifuge system. Annual Report of the Ministry of Health and Welfare, Research Committee for Hemolytic Disease, Japan, p. $225,1976$.

3) Honda M, et al: Method of assay for human suppressor $\mathrm{T}$ cell activity. Clinical Immunology 13: $460,1981$.

4) Kotani K, et al: A case of autoimmune hemolytic anemia with anti-e specificity - investigation of cellmediated immunity. Presented at Meeting of the Japan Hematological Society of Chugoku and Shikoku Districts in Tokushima, 1982.

5) Ogawa $\mathrm{H}$, et al: Effect of irradiation on the treatment of NZB/NZW disease. Presented at Annual Meeting of the Treatment of the Connective Tissue Diseases Research Committee supported by the Ministry of Health and Welfare of Japan, Tokyo, 1982.

This work was supported by the Grant in the Idiopathic Erythropoietic Disorders and the Treatment of the Connective Tissue Diseases Research Committees and Grant-in-Aid for Scientific Research, 1981 (00557163).

\title{
(7) Platelet Abnormality in the Systemic Disorders
}

\author{
Atsushi Kuramoto, MD \\ Department of Internal Medicine, Research Institute for Nuclear Medicine and Biology, \\ Hiroshima University
}

Platelet abnormality denote clinically quantitative decrease in number and also abnormality in quality; defective function and hypersensitive hyperfunction in both ways.

In this report, the character of abnormality in platelets is described morphologically and biochemically, to indicate what are the reliable indices of those abnormalities.

\section{The Function of Platelets and Identification of Platelet Granule Contents.}

Platelets contain three kinds of granules; alphagranule, dense granule and mitochondria. At present, it has been demonstrated and accepted that alpha-granule contains potassium, fibrinogen, growth factor, platelet factor 4, beta-thromboglobulin, fibronectin, permeability factor and chemotactic factor and that dense granule contains 5-hydroxytryptamine, ADP, ATP, calcium, pyrophosphate and antiplasmin. The separation and identification of those substances are important to make clear the function of platelets per sec and the extent of platelet participation in the development of systemic diseases. Taketomi, Y. et al identified platelet factor 4 in human platelets and megakaryocytes by light microscopy, using an indirect immunoperoxidase (PAP) method with monospecific rabbit antihuman platelet factor 4 antiserum. Platelets and megakaryocytes were shown to contain positive brownblack staining materials localized in granule like particles in the smears of the peripheral blood and bone marrow, respectively. No other cells contain specific positive staining material. The intracellular localization of PF 4 in platelets has been more precisely defined to alpha-granules by immunoelectronmicroscopy. Fibronectin prepared from human plasma was also identified in the platelets as well as megakaryocytes by immunoperoxidase staining. These results provide provocative evidence that 